\title{
How to do things with brackets
}

\section{The epoché explained}

Overgaard, Søren

Published in:

Continental Philosophy Review

DOI:

10.1007/s11007-015-9322-8

Publication date:

2015

Document version

Peer reviewed version

Document license:

Unspecified

Citation for published version (APA):

Overgaard, S. (2015). How to do things with brackets: The epoché explained. Continental Philosophy Review, 48(2), 179-195. https://doi.org/10.1007/s11007-015-9322-8 


\section{How to do things with brackets: The epoché explained}

Søren Overgaard

\section{Abstract}

According to 'purification interpretations', the point of the epoché is to purify our ordinary experience of certain assumptions inherent in it. In this paper, I argue that purification interpretations are wrong. Ordinary experience is just fine as it is, and phenomenology has no intention of correcting or purifying it. To understand the epoché, we must keep the reflective nature of phenomenology firmly in mind. When we do phenomenology, we occupy two distinct roles, which come with very different responsibilities. As reflecting phenomenologists, we must deactivate all our beliefs about the world. But the only point of this is to be able to describe the experiences we have as experiencing subjects, including all those beliefs about the world that may be part and parcel of those experiences. I end by suggesting that there is a useful analogy between phenomenological reflection and the familiar practice of quoting.

Philosophy ... leaves everything as it is.

(Wittgenstein 1963: § 124)

If ... the reflection is not to presume upon what it finds and condemn itself to putting into the things what it will then pretend to find in them, it must suspend the faith in the world only so as to see it ... (Merleau-Ponty

\section{Introduction}


Few phenomenological notions are as fraught with controversy as Husserl's 'phenomenological epoché'. One important reason for this, as I suggest in this paper, is that the epoché is not well understood. As I will show, the fundamental mistake readers make again and again is to think the point of the epoché is to 'purify' our supposedly biased or impure ordinary experiences. Disagreement then revolves around precisely which aspects of our experience the epoché is primarily intended to target, and around the further question of whether Husserl is right to think that any such purification is called for. But the whole thing is based on a misunderstanding. Ordinary experience is just fine as it is. Phenomenology aims to describe and analyse it, as well as outline its conditions of possibility; it has no intention of correcting it or disregarding aspects of it.

As I will suggest, commentators may miss this point because they do not fully appreciate the implications of the reflective nature of phenomenology. When we do phenomenology, we are wearing two hats, as it were: on the one hand, we are subjects of 'straightforward experience'; on the other hand, we are reflecting phenomenologists. Everything depends on distinguishing clearly between these two roles. As phenomenologists, we are supposed to 'bracket' beliefs about the existence or metaphysical nature of intended objects. But this does not - indeed, as we will see, must not - affect the reflected-upon experience in any way. Phenomenological descriptions under epoché, I will suggest, should be understood as efforts to 'quote' the experiences reflected upon, that is, recount how things are 'according to the experience', without either endorsing or rejecting that picture of things.

The paper is structured as follows. In the next section, I briefly review some of the key points Husserl makes about the epoché. Then, in section 3, I provide various examples of the 'purification interpretations' with which I want to take issue. In Section 4, I question each individual purification interpretation in turn and offer some general reasons to think no such 
interpretation could be right. Finally, in section 5, I outline what I think is the correct interpretation of the epoché, centred on an analogy between phenomenological reflection and the familiar practice of quoting.

\section{The point of bracketing}

Let me begin by marking an important distinction between the epoché and the so-called 'transcendental reduction'. Husserl occasionally makes such a distinction, but by no means consistently; nor do all of his commentators. ${ }^{1}$ For present purposes, we need not commit to any particular interpretation of the transcendental reduction. We can simply note that it is intimately connected with Husserl's project of unearthing the transcendental preconditions for worldexperience; preconditions Husserl ultimately locates in transcendental (inter)subjectivity. Although the epoché for Husserl constitutes an important first step towards the realization of that project, the former can also be performed independently of the latter.

What, then, is the epoché? In order to reply to this question, let us begin by considering two remarks by Husserl of the sort that motivate the readings I am going to suggest are misguided. In Ideas I, Husserl writes:

We put out of action the general positing which belongs to the essence of the natural attitude; we parenthesize everything which that positing encompasses with respect to being: thus the whole natural world which is continually 'there for us', 'on hand'... If I do that, as

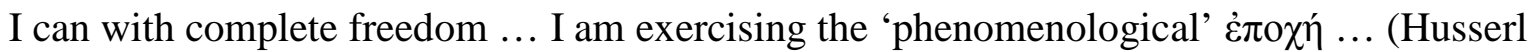
$1983,61)$

\footnotetext{
${ }^{1}$ See Zahavi $(2003,46)$ and A. D. Smith $(2003,27)$ for commentators who do make this distinction.
} 
Almost two decades later, in the Cartesian Meditations, Husserl essentially repeats the point:

This universal depriving of acceptance, this 'inhibiting' or 'putting out of play' of all positions [aller Stellungnahmen] taken toward the already-given Objective world and, in the first place, all existential positions (those concerning being, illusion, possible being, being likely, probable, etc.) [is called the] 'phenomenological epoché'... (Husserl 1995, 20)

Taking certain positions vis-à-vis the so-called objective world belongs to the essence of the 'natural attitude' - the pre-philosophical, or perhaps more accurately pre-phenomenological, attitude in which we tend to live most of our lives. ${ }^{2}$ And to perform the epoché is to 'inhibit', 'put out of play' or 'out of action', or 'deprive of acceptance', those positions. While Husserl emphasizes that such inhibiting (etc.) 'in the first place' applies to existential position-taking, he seems equally clear that it ultimately applies to each and every position-taking. I take it that includes beliefs not only about the existence (or non-existence, etc.) of objects in the world, but also about their intrinsic and relational properties, about the laws governing their behaviour, and so on.

What is the purpose of such bracketing? According to Husserl, it allows us to 'gain possession of something' $(1995,20)$, indeed something that is crucial to the phenomenological project. Phenomenology is essentially a descriptive enterprise. It aims faithfully to describe our experiences, including the world as it shows up in our experiences. As Husserl's 'principle of all principles' stipulates, we must accept our experiences simply as they present themselves to us, without adding or subtracting anything (Husserl 1983, 44). In the Crisis, Husserl expresses the same point as follows: 'The first thing we must do, and first of all in immediate reflective self-experience,

\footnotetext{
${ }^{2}$ Much philosophy, it seems to me, is carried out in what Husserl calls the natural attitude.
} 
is to take the conscious life, completely without prejudice, just as what it quite immediately gives itself, as itself, to be' (Husserl 1970, 233). Husserl believes it is precisely the epoché that secures the phenomenologist's possession of that thematic field. In other words, by performing the epoché, I gain possession of

my pure living, with all the subjective processes making this up, and everything meant in them, purely as meant in them: the universe of 'phenomena' in the ... phenomenological sense. (Husserl 1995, 20-21)

Husserl's thought is that without inhibiting or deactivating all our assumptions about the world, these are liable to influence and hence falsify our phenomenological descriptions. What matters here is not the fact that many of these assumptions may be false. Even the most well-established knowledge must be bracketed if we are to secure access to our experiences and their objects purely as experienced. Even known truths - perhaps especially known truths - may lead us astray when our aim is to do phenomenology.

What may happen is not dissimilar to the phenomenon known as 'the curse of knowledge'. ${ }^{3}$ This refers to the difficulties someone who knows something may have with imagining not knowing it, and hence with predicting what someone not in the know will think or do. Thus, someone tapping a popular tune will tend to think it much easier than it actually is for others to guess which tune is being tapped. To achieve the right understanding of what it is like to guess a tune from the available stimulus, we precisely need to 'bracket' our knowledge, inhibit it, but this may be very hard to do. Perhaps there may even be a sense in which the person in the know may

\footnotetext{
${ }^{3}$ See Heath and Heath 2007.
} 
find it hard to gauge what the available auditory information actually is - their knowledge preventing them from forming an accurate impression of the sounds that are actually 'out there'.

When describing, say, our visual perceptual experience as we live through it, a similar problem can arise. An example may help to illustrate this. In Intentionality, John Searle's contends that visual perceptual experiences are 'causally self-referential'. What he means thereby is that they have contents of a type exemplified by the parenthesized portion of the following:

I have a visual experience (that there is a yellow station wagon there and that there is a yellow station wagon there is causing this visual experience). (Searle 1983, 48)

Searle may not intend this to reflect our visual experiences 'just as experienced', though it is a very common thought that the content of a perceptual experience precisely does reflect how things appear to the subject of the experience. ${ }^{4}$ If that is also Searle's view, then this could be a case in which knowledge about the world - in this case, about vision - is smuggled into, and potentially falsifies, the description of the experience. Look at something in front of you. Does it seem to you that the presence of that thing is causing your experience? I, for my part, am not aware of any such causally self-referential content.

Whether or not Searle's account is a phenomenologically accurate description of our visual experiences, the general point is hopefully clear: We need to bracket all our assumptions concerning the world, including all we know and think we know about the world, if we want to achieve a secure grasp of our experiences 'purely as' we live through them.

\section{Purification interpretations}

\footnotetext{
${ }^{4}$ Searle gestures at thoughts in the vicinity, e.g. when he writes that 'a report of how it seemed to the agent is, in general, a specification of the Intentional content' (Searle 1983, 42). This formulation is, however, compatible with the claim that not all specifications of the content reflect how things seem to the agent.
} 
We should now have a rough notion of the purpose of the epoché, and of the terms in which Husserl describes the procedure. As for the latter, it has seemed to many of Husserl's readers that the epoché asks us to remove or, perhaps better, deactivate certain elements that are inherent in our ordinary (pre-philosophical) experience and acting. Many have taken issue with this idea, often on the grounds that it seems contrary to the descriptive spirit of phenomenology. Indeed, according to Taylor Carman, 'most representatives' of the phenomenological movement have 'rejected the epoché as a phenomenologically unmotivated dogma' (Carman 2005, 76). Interpreters have, however, tended to identify somewhat different position-takings as the ones most affected by the phenomenologist's brackets. Stanley Rosen, for example, focuses on position-taking with respect to values:

[I]t seems to me that the time has come for a return to ordinary experience. ... The return I contemplate is not quite that of the Husserlian phenomenology of the Lebenswelt ... I do not recommend an Ausschaltung or switching-off of our existential immersion in the value-saturated stream of everyday life, since it is precisely this value-saturated character that I take to be our starting point. (Rosen 1999, 234)

According to Tyler Burge, the method of bracketing leads rather straightforwardly to a sense-datum theory of perception, because it severs the connection between the contents of perceptual experience and the physical environment:

Husserl assumes, in his 'bracketing' method of phenomenological reflection, that it is possible to understand the nature and content of perception ... without any consideration of perceptual reference to the physical environment. ... [H]e construes 
[perceptual] contents as not already implying reference and attribution to the physical environment. In this respect, Husserl's conception of perception is very like that of the phenomenalists/sense-data-theorists inspired by Russell. (Burge 2010, 131)

Burge's point, presumably, is that the putting out of play of the positing of physical, mindindependent objects leaves only mind-dependent entities like sense-data for our experiences to be experiences of. Carman pursues a similar point, though his is not restricted to perception. He observes that:

The phenomenological epoché ... consists in bracketing or abstracting from all objects transcendent to consciousness in order to reflect on the contents immanent within it. (Carman 1999, 208-9)

Echoing Carman's claim that the majority of phenomenologists have rejected the epoché, H. P. Steeves asserts that

Husserl has been taken to task by everyone from Heidegger and Merleau-Ponty to Levinas and Derrida for not dealing with the reality of ... phenomena. Such criticisms are typically well-taken, though the later-Husserl surely realized some of the need to return to the world and its things. (Steeves 2006, xiii) $)^{5}$

\footnotetext{
${ }^{5}$ Steeves is right to suggest that such criticisms - and the interpretations of the epoche on which they are based - have a long history within the phenomenological movement. Herbert Spiegelberg, the great historian of the movement, essentially voiced those very criticisms more than seven decades ago (Spiegelberg 1940, 93). But for some doubts about Steeves' portrayal of Heidegger here, see Overgaard 2010. For similar doubts concerning Merleau-Ponty, see J. Smith 2005 .
} 
Again, of course, the culprit is the epoché. But as Steeves reads the later phenomenologists and post-phenomenologists, their complaint is not specifically that the 'transcendence' of objects that is inhibited or put out of play. Rather, their - in Steeves' eyes justified - charge is that the 'reality' of objects is bracketed, and ought not to be.

Steeves' focus on the 'reality of phenomena' finds some prima facie support in the fact that Husserl himself singles out 'existential' positing as what should first and foremost be bracketed. But the fact that Husserl recommends such bracketing is of course not sufficient to show that the criticisms are on target. We are still without a basis for claiming that we ought not to bracket at least some of our existential assumptions. According to Lilian Alweiss' (2013) recent defence of Husserl, critics make the mistake of thinking that the epoché implies somehow denying or disregarding the reality, existence or mind-independence of the world and objects in the world tout court, whereas in actual fact it only purges our experience of a particular - and highly problematic - interpretation of what such existence involves. Alweiss writes:

Phenomenological bracketing does precisely what it says: it 'brackets' the realist and, indeed, theoretical presupposition implicit in all our straightforward experiences of the world and its objects, namely, that the world and its objects are in a strong sense mind-independent. (Alweiss 2013, 455-56)

Alweiss describes the effect of such bracketing in terms of its 'point[ing] to a theory-free or purified way of seeing the world' (Alweiss 2013, 460). To do phenomenology, we need something like the epoché, she thinks, 'because it is only through critique or genuine doubt that our seeing can be purified from theory' (Alweiss 2013, 459). Contra Husserl's critics, the epoché purges our experience of a theory we should not want to retain anyway: it is a 'realist assumption' (Alweiss 
2013, 456) that may be 'implicit in all our straightforward experiences' but is no less 'unreasonable' for all that (Alweiss 2013, 455). ${ }^{6}$ Purifying our experience from metaphysical realist assumptions, contra Burge and Carman, is entirely consistent with recognizing the mind-independence of objects. We see things like tables and trees, and these are not immanent to consciousness. Indeed, the epoché precisely permits us to recognize that tables and trees 'present or manifest themselves as mind-independent [objects] existing in a world' (Alweiss 2013, 458). On the Husserlian picture, this is how they 'constitute' themselves for the experiencing subject (Alweiss 2013, 459). All that this is inconsistent with is metaphysical realism's denial that the nature and existence of material things depend in any way upon a subject's actual or possible experience.

This is not the place to discuss Husserl's so-called 'transcendental idealism', of which Alweiss provides an essentially correct outline. I only want to call attention to the fact that she agrees with Husserl's critics that the epoché purifies our experience from certain assumptions 'implicit in all our straightforward experiences of the world and its objects', to quote Alweiss (2013, 455) again. That is, Alweiss and the other interpreters discussed in this section offer purification interpretations of the epoché. According to such interpretations, the point of the epoché is to cleanse our straightforward experiences of some supposedly problematic presuppositions inherent to them. To be sure, Alweiss and the other interpreters disagree about just what the purification targets: does it mainly target assumptions about value, about the transcendence of perceived objects, about their status as real - or is it rather the realist assumption that the physical world is in 'a strong sense' mind-independent? ${ }^{7}$ There is also disagreement about whether or not such purification is

\footnotetext{
${ }^{6}$ These considerations ultimately lead Alweiss to claim that, for Husserl, 'The natural attitude is not natural at all. It is imbued with theoretical assumptions' $(2013,459)$. But since she also (correctly) describes the natural attitude as one that 'defines all aspects of our life' (Alweiss 2013, 450), it seems the obvious conclusion to draw would not be that the natural attitude is not natural, but that certain theoretical assumptions come very naturally to us. One wonders what sort of 'attitude' might qualify as natural in Alweiss' eyes, since it would apparently have to be devoid of all theoretical sedimentations. Surely, all adult experience contains sediments of years of education. Are only newborn infants in a properly 'natural' attitude?

${ }^{7}$ Perhaps other disagreements are also worth highlighting. An anonymous referee suggests that I am lumping together two very different sorts of views under the heading of 'purification interpretations': on the one hand 'reductionist'
} 
needed. But these differences are not very important, in my view, since, as we are about to see, the epoché is not supposed to purify or cleanse our 'straightforward experience' of anything whatsoever. What we need to 'purify', if this term is at all appropriate here, is our description of our straightforward experience. ${ }^{8}$ The latter itself must be left entirely as it was.

\section{Against purification interpretations}

In this section, I first want to present some (inconclusive, though suggestive) reasons for thinking that none of the purification interpretations sketched in the previous section is correct as it stands. After that, I offer some considerations that I believe challenge any purification interpretation. So, first of all, I think our suspicions vis-à-vis the purification interpretations we have outlined should be raised when we notice that Husserl seems to contradict every single one of them. Rosen, as we have seen, seems to think the epoché purges our experiences of their 'value-saturated' character. Bracketing, then, is supposed to annul any positing of value our experiences may involve. But this squares very poorly with some of Husserl's remarks on the issue. Discussing how a blossoming apple tree appears in perception when the epoché has been performed, Husserl remarks that

everything remains as of old. Even the phenomenologically reduced perceptual mental process is a perceiving of 'this blossoming apple tree, in this garden,' etc., and

views that reduce the experienced object to some sort of mind-dependent or immanent entity, and on the other hand 'eliminativist' views that think of the epoché as inhibiting or deliberately ignoring certain assumptions characteristic of the natural attitude. Only the latter, it might be claimed, truly deserve to be called 'purification interpretations'. It seems to me that, with the exception of Burge's, none of the interpretations I have mentioned fit the reductionist pattern, however. And even in Burge's case, the 'reduction' seems merely the flipside of the 'elimination' of the physical environment. (To repeat: as I read him, Burge is suggesting that, since the epoché severs all bonds to the physical environment, we are only left with non-physical entities for our experiences to be experiences of. The italicized bit is the 'eliminative' move.) So it seems to me that I am justified in treating all the mentioned positions as examples of 'purification interpretations'.

${ }^{8} \mathrm{I}$ am grateful to an anonymous referee for urging me to make this point explicit. 
likewise, the reduced liking is a liking of this same thing. The tree has not lost the least nuance of all these moments, qualities, characteristics with which it was appearing in this perception, <with which> it <was appearing as> 'lovely,' 'attractive,' and so forth in this liking. (Husserl 1983, 216)

It evidently is not Husserl's view that bracketing has any effect at all on the value-saturated character of our experience. If the apple tree appears lovely or attractive in our straightforward experience of it, then it retains every nuance of these qualities when we apply the brackets. As for the suggestion that bracketing implies a construal of the contents of perception in purely immanent terms, devoid of reference to the physical environment, Husserl has this to say:

I perceive the physical thing, the Object belonging to Nature, the tree there in the garden; that and nothing else is the actual Object of the perceptual 'intention.' A second immanental tree, or even an 'internal image' of the actual tree standing out there before me, is in no way given, and to suppose that hypothetically leads to an absurdity. (Husserl 1983, 219)

Indeed,

For everyone except confused philosophers it is absolutely without question that the thing perceived in perception is the physical thing itself, in its own factual being [in seinem selbsteigenen Dasein]... (Husserl 1969, 281) 
But could Husserl construe 'physical thing' in mental terms, say as 'constructions out of sense data'? It seems unlikely:

Here, in immediate givenness, one finds anything but color data, tone data, other 'sense' data or data of feeling, will, etc.; that is, one finds none of these things which appear in traditional psychology, taken for granted to be immediately given from the start. Instead, one finds ... intentionality, in those familiar forms which, like everything actual in the surrounding world, find their expression in language: 'I see a tree which is green; I hear the rustling of its leaves, I smell its blossoms,' etc. (Husserl $1970,233)$

In fact, Husserl never tires of emphasizing how a physical thing such as a tree or a table is experienced 'as a transcendent perceptual object, precisely as an object that is more than what we directly perceive, as an object that can completely vanish from my perception and yet still persist' (Husserl 2001, 52). Husserl even seems to contradict Steeves' interpretation, which appeared to cohere so well with Husserl's emphasis on 'existential' presuppositions as the primary targets of bracketing:

through the epoché a new way of experiencing, of thinking, of theorizing, is opened to the philosopher; here, situated above his own natural being and above the natural world, he loses nothing of their being and their objective truths and likewise nothing at all of the spiritual acquisitions of his world-life or those of the whole historical communal life; (Husserl 1970, 152) 
This quote, in conjunction with the quote from Formal and Transcendental Logic (Husserl 1969) concerning the object of perception, suggests that there is no straightforward sense in which the epoché is supposed to deprive phenomena of their 'reality'.

That leaves Alweiss' interpretation. Could it be that the epoché has a more limited target - a realist assumption embedded in our experiences? The main difficulty that applies specifically to this interpretation is Husserl's claim that although existential positing has a certain priority, we ultimately need to bracket 'all positions [aller Stellungnahmen] taken toward the already-given Objective world' (1995, 20; emphasis added). That hardly suggests a narrow target along the lines proposed by Alweiss.

Even if I am right that there is good reason to doubt each of the purification interpretations we have considered, it does not follow that no purification interpretation is right. There could be other such interpretations besides the ones I have discussed. Indeed, it might also be suggested that my case against Alweiss' interpretation is weak: perhaps the single instance where Husserl suggests that we need to bracket 'all positions' is simply a slip of the pen, or at any rate does not reflect his considered view. But as I will now show, there are general reasons for thinking that no purification interpretation could be correct.

First of all, purification interpretations seem to be in tension with the very idea of phenomenology. As already explained, phenomenology aims faithfully to capture our experiences as we live through them, including their intentional objects precisely as they show up in our experiences. So if, in our straightforward experiences, we accept the world 'as actually existing', or as mind-independent in whatever sense, then these presuppositions, too, must be accurately recorded, not removed or altered, or in any way tampered with. To do so would be to violate the basic principles of phenomenology. Nor is this something Husserl himself failed to realize. In the Cartesian Meditations, for example, he emphasizes that the phenomenological description of the 
perception of a house encompasses 'the house-perception with all its moments, which belonged to it before [i.e., before the brackets were introduced] and are continuing to take shape' (Husserl 1995, 34). As if it were not already abundantly clear that this means that all moments of the straightforward experience have to be retained, Husserl goes on to emphasize specifically that:

There is lacking neither, on the one side, the existence-positing (perceptual belief) in the mode of certainty, which is part of - normal - perceiving, nor, on the other side (that of the appearing house), the character of simple 'factual existence' [schlichten Daseins]. (Husserl 1995, 35)

Clearly, Husserl does not think that straightforward, pre-phenomenological experience should be subjected to any purification. If we experience the world as 'actually existing', as no doubt we do, then to purify our experience of that existential position is precisely to modify the very thing it was our task faithfully to describe. It seems somewhat less obvious that, in our pre-philosophical life, we experience the world as being mind-independent 'in a strong sense'. But if we do, then again, purifying our experience of that intrinsic realism alters what we merely had to record. Quite generally, if the point of phenomenology is to describe our pre-phenomenological experiences, then doing phenomenology cannot involve cleansing, purifying, or in any other way changing those experiences. In the words of A. D. Smith, it is in fact 'absolutely vital that, as far as the content of our natural experience is concerned, the epoche leaves everything exactly as it is' $(2003,23){ }^{9}$

Many other things Husserl says yield the same conclusion. In the epilogue to Ideas 1, for example, he emphasizes that the 'sole task' of phenomenology 'is to clarify the sense of this world, precisely the sense in which everyone accepts it - and rightly so - as actually existing

\footnotetext{
${ }^{9}$ Sokolowski $(2000,190)$ makes the same point: 'We must leave everything as it was, for otherwise we would change the very thing we wish to examine'.
} 
[wirklich seiend]' $(1989,420)$. This is echoed in the Cartesian Meditations, when Husserl remarks that 'phenomenological explication does nothing but explicate the sense [the] world has for us all, prior to any philosophizing ... - a sense which philosophy can uncover but never alter' (Husserl 1995, 151; emphasis removed). Presumably, the 'sense' (Sinn) the world has to us all prephilosophically refers to the world as experienced by us, as we all experience it to be. Philosophy cannot alter that sense, Husserl thinks, but only uncover it. But again, to 'purify' experience in any way, to deactivate any presuppositions vis-à-vis the world that may be inherent in it, is precisely to tamper with the sense the world has for us, to alter or edit that sense.

In summary, it seems as if purification interpretations get the very idea of bracketing wrong. It does not follow that they misconstrue the purpose of epoché. Alweiss, for example, says precisely the right thing about the latter. As we have seen, the epoché is indeed supposed to permit us to 'describe experience just as it is experienced' (Alweiss 2013, 456). But the purification of our experiences that she envisages does not leave them intact just as they are experienced. It therefore does not serve the purpose the epoché was supposed to serve. ${ }^{10}$

\section{The epoché explained}

At first blush, it may seem as if we have landed ourselves in something of a paradox. We need to bracket all our assumptions about the world in order to secure our access to our experiences just as they are lived through. Yet inhibiting all our assumptions is what we must not do, on pain of changing the very experiences we wanted to describe. Someone might find it tempting to apply to

\footnotetext{
${ }^{10}$ Note that the point here is not to contest Alweiss' interpretation of Husserl as being critical of metaphysical realism. What I object to is her interpretation of the epoché as a purification of straightforward experience, a deactivation of some presupposition inherent in it.
} 
the case at hand what Kierkegaard notoriously said about marriage: Bracket, and you will regret it. Do not bracket, and you will regret that too. ${ }^{11}$

But if it looks that way it is because we have forgotten to take the essentially reflective nature of phenomenology into account. Phenomenology requires us to wear two hats, as it were: on the one hand, we are subjects of 'straightforward experience'. And on the other hand, we are phenomenologists reflecting on that straightforward experience. Distinguishing clearly between these two roles is the key to a proper understanding of the epoché. As phenomenologists, we are supposed to 'bracket' all our beliefs about the existence or metaphysical nature of intended objects, and that does mean inhibiting them, deactivating them, putting them out of play. That is to say, we must deactivate all our positions with respect to the value, mind-dependence or independence (whether 'strong' or 'weak') of the experienced objects, and even our positions vis-à-vis the reality of those objects. But, crucially, this must not affect the reflected-upon experience in any way: its positions with respect to reality, value, etc. must be left untouched. For they are part of that which we want faithfully to describe. Husserl phrases the crucial point vividly, if somewhat dramatically, in terms of a distinction between two 'egos':

The non-participating, the abstaining, of the Ego who has the phenomenological attitude is his affair, not that of the perceiving he considers reflectively, nor that of the naturally perceiving Ego. (Husserl 1995, 35)

As he continues, the phenomenological reflection thus involves an Ichspaltung, 'a splitting of the Ego' (Husserl 1995, 35). Husserl's claim is of course not that henceforth there literally are two

\footnotetext{
${ }^{11}$ Compare: 'Marry, and you will regret it. Do not marry, and you will also regret it. Marry or do not marry, you will regret it either way' (Kierkegaard 1987, 38).
} 
distinct egos present. ${ }^{12}$ In the standard case, the reflecting, phenomenologically attuned ego, and the ego whose experiences are reflected upon, remain one and the same. Husserl's phrasing does, however, make it vivid that in such a case, the phenomenologist is occupying two very different roles, which come with very different responsibilities. In order faithfully to capture the reflectedupon experiences with all the inbuilt assumptions they may have, we - the would-be faithful describers - must deactivate all our assumptions. As Husserl writes in Ideas 1,

As phenomenologists we abstain from all such positings. But on that account we do not reject them by not 'taking them as our basis', by not 'joining in' them. They are indeed there, they also essentially belong to the phenomenon. Rather we contemplate them; instead of joining in them, we make them Objects, take them as component parts of the phenomenon ... (Husserl 1983, 220; emphasis in the original)

It must be conceded, though, that there is something slightly odd - in a 'splitpersonality' sort of way - about this whole business. ${ }^{13}$ Some of the very same 'positings' that we qua phenomenologists - must deactivate are positings that we - qua experiencing subjects - do not deactivate. For example, we (= phenomenologists) must inhibit all belief in the mind-independent existence while we (= experiencing subjects) continue to 'live' such beliefs, without the slightest inhibition. But there are at least two reasons why the strangeness of this must not be exaggerated.

First, it is far from clear that what Husserl has in mind is a situation in which one person simultaneously occupies both roles. Rather, he frequently speaks of phenomenological reflection in terms of a relation to an 'earlier' experience (e.g. Husserl 1995, 34). That is to say, he

\footnotetext{
${ }^{12}$ If all phenomenology were what Dennett (1991) calls 'heterophenomenology', then that would be the case. But this is not Husserl's view.

${ }^{13}$ Indeed, Eugen Fink referred to this Ichspaltung at the heart of the phenomenological method as a kind of 'methodological schizophrenia' (Fink 2004, 51). Thanks to an anonymous referee for drawing this passage to my attention.
} 
seems to envisage a procedure in which the phenomenologists reflect on a past experience, perhaps still held in retention. Importantly, this experience was experienced straightforwardly, with all that this involves for a naturally attuned subject. It is only in the subsequent reflection that the brackets are put in place. But if we are not required simultaneously to both bracket and not bracket our natural positings, but to alternate between experiencing in an 'unbracketed' manner, and reflecting on previous experiences (now with the brackets in place), the recommended procedure seems much less mysterious. ${ }^{14}$

Secondly, even if phenomenology did require us to occupy both roles simultaneously, the question is whether this would be so odd or unnatural. We find a somewhat similar state of affairs, for example, in cases of illusions exposed as such. When looking at the Müller-Lyer lines that you know to be the same length, one still looks to be longer than the other. That is to say, your visual experience continues to 'posit' that one line is longer than the other, while you posit an incompatible state of affairs. In a related sort of case, we may simply be unsure about whether to 'believe our eyes'. In such a case, we may enjoy an experience that is committal in some way about our environment - e.g. presents a dagger as floating in mid-air before us, as in Macbeth. But, perhaps reflecting on the unlikely content of the experience, we refrain from 'going along with it'. Performing the epoché may perhaps involve a temporary 'split personality' of sorts, then, but it is not the case that such a state of affairs is entirely without precedent in natural life.

If this all still sounds rather abstract, it might be helpful to compare bracketing with the familiar practice of quoting. ${ }^{15}$ Husserl in fact suggests this himself when he speaks of 'inverted commas' or 'quotation marks' (Anführungszeichen) (Husserl 1983, 216, 220) instead of brackets. When you quote someone, you reproduce their spoken or written words. But that is obviously not

\footnotetext{
${ }^{14}$ Again, I am indebted to an anonymous referee for pressing this point.

${ }^{15}$ This comparison was originally made in Sokolowski 1984. As Sokolowski writes, Husserlian 'bracketing can be seen as an analogue to the quoting we execute when we converse' (1984, 718). See also D. W. Smith 2007, 244-49. I thank my two referees and Dan Zahavi for drawing these texts to my attention.
} 
sufficient. You reproduce someone's words also when you repeat what they said because you want to express your agreement with them ('I agree with Karen: Annie Hall is Allen's best movie'). But stating what someone else stated is not quoting them. One the other hand, merely referring to what someone else said ('What John said the other day') is not quoting them either. As Sokolowski (1984, 702) points out, one of the remarkable things about quoting is that when we quote, our words both refer to what someone said and 'contain' what they said. What is particularly important for our purposes is that by quoting someone we do thereby assert what that person asserted. By writing,

\section{Karen said: 'Snow is white'}

I have asserted that someone said something about the colour of snow. I have not asserted anything about the colour of snow. ${ }^{16}$ I have neither affirmed nor denied that snow is white, nor have I surmised, questioned, or doubted anything about the colour of snow. One may of course quote something in order to show its truth, falsity, and so on, ${ }^{17}$ but the point is that, in and of itself, to quote is to do none of these things. Furthermore, in order to produce an accurate quote you must focus on faithfully recounting what the person said, as opposed to what you might know or believe about the subject matter the person spoke about. ${ }^{18}$ That is to say, for the purposes of quoting, you must 'bracket' whatever knowledge you have pertaining to the matter addressed - it must not be allowed to interfere with your recounting of what was said. Similarly, in phenomenology, the brackets are imposed simply in order to ensure that we are impartial reporters of our own

\footnotetext{
${ }^{16}$ Nor (I am happy to say) did I assert anything about the consequences of marrying or not marrying when I quoted Kierkegaard on the topic in note 11 above.

${ }^{17}$ Indeed, as Sokolowski observes, one can quote 'doubtfully, assuredly, with probability or with certainty, suspiciously or mockingly' $(1984,705)$.

${ }^{18}$ Which is not to say that you are not supposed to be concerned with the subject matter, but only with the person's choice of words, for example. See the next footnote.
} 
experience, as it were. And, pace the purification interpretations, that means faithfully reporting everything the experience 'says' 19

P. F. Strawson offers a vivid illustration of (what is essentially) the epoché in a passage Alweiss also cites. Strawson imagines what would happen if we asked a non-philosopher observing a rural scene through a window to describe his or her visual experience.

Uncautioned as to exactly what we want, he might reply in some such terms as these: 'I see the red light of the setting sun filtering through the black and thickly clustered branches of the elms; I see the dappled deer grazing in groups on the vivid green grass ...'; and so on. (Strawson 2011, 127)

As Strawson goes on to say, what we as philosophers want is a description that confines itself to recording what is experienced, without smuggling into that description assumptions about the (mind-independent, physical) world. But our subject's report - mentioning 'the sun', 'the elms', the 'dappled deer', and so on - is replete with such assumptions. We therefore ask the person to amend his account so that, without any sacrifice of fidelity to the experience as actually enjoyed, it nevertheless sheds all that heavy load of commitment to

\footnotetext{
${ }^{19}$ Let me briefly indicate one other respect in which phenomenological descriptions under epoché may be compared with quoting. Typically, when we quote someone, we are still concerned with the thing the person quoted is concerned with. That is to say, we are not focussing exclusively on what is going on within that other person's mind, or on the words coming out of her mouth. When I quote Karen's statement about Annie Hall, I am still dealing with Annie Hall, but as viewed through Karen's eyes, so to speak (see Sokolowski 1984, 700). Perhaps an even clearer case is the following: 'What did Mummy say?' - 'She said the sidewalk is slippery today'. Clearly, the point of asking the child to recount the mother's warning is to ensure the child sees the sidewalk in a particular way - namely, as the mother sees it. The child is not supposed to become preoccupied with the mothers mental states, or with her choice of words. In a similar manner, phenomenological descriptions - as Husserl emphasizes repeatedly - do not exclude the world in order to focus on our subjective experiences. Rather, the world remains our focus, but precisely as it shows up in the experiences we are describing (for a particularly clear statement, see Husserl 1997, 494). (D. W. Smith (2007) offers a somewhat different reading here, which I do not have space to discuss.)
} 
propositions about the world which was carried by the description he gave. We want an account which confines itself strictly within the limits of the subjective episode, an account which would remain true ... even if he had been subject to total illusion. (Strawson 2011, 127-28)

Although the restrictions Strawson describes here are those he finds in a certain kind of empiricist philosopher of perception, ${ }^{20}$ the restrictions are clearly those of the epoché as well. And, as philosophically unschooled as Strawson's imaginary person is, he evidently knows how to apply the brackets. For the person

does not start talking about lights and colours, patches and patterns. For he sees that to do so would be to falsify the character of the experience he actually enjoyed. He says, instead, 'I understand. I've got to cut out of my report all commitment to propositions about independently existing objects. Well, the simplest way to do this, while remaining faithful to the character of the experience as actually enjoyed, is to put my previous report in inverted commas or oratio obliqua ... I render the perceptual judgement internal to the characterization of the experience without actually asserting the content of the judgement...' (Strawson 2011,128)

This is exactly what we do when we offer phenomenological descriptions under epoché: we quote our experiences, without asserting (or denying) their implicit 'claims'; indeed, we make a conscious effort to avoid relying on any assumptions whatever about the nature or reality of the world. What Husserl would want to add to Strawson's description is that it is in fact the brackets that secure our

\footnotetext{
${ }^{20}$ The quoted passages appear in a critical discussion of Ayer's sense-datum theory of perception.
} 
reflective hold on the experience as actually lived through. The description of our experience should contain no commitments to propositions about the world, except in inverted commas, and only insofar as these commitments are found to be internal to the experience. And so to ensure that no commitments unduly influence our descriptions and make us 'misquote' our experiences, we, as phenomenologists, must deactivate them all. There are three crucial points here. Before concluding, let me recapitulate them:

1. No 'positions' towards the experienced world may appear in the description, except in inverted commas. The description may contain no (unbracketed) commitments to propositions about the world. As phenomenologists, we need to inhibit all our commitments.

2. All positions internal to the reflected-upon experience must figure in the description, and only such positions may figure in it. Just as we must not remove positions or commitments from the reflected-upon experience, we must not add any to it.

3. It is by inhibiting all our positions (i.e., 1) that we secure 'impartial' access to the experience and its positions (i.e., 2). Relying on none of our positions - being to that extent 'impartial' - we are in a position faithfully to report which commitments the experience itself contains.

\section{Conclusion}

To conclude, I have suggested that 'purification interpretations' of the epoché are misguided. Contra such interpretations, purifying our experiences of any assumptions inherently belonging to them would be to change that which we were supposed to describe. I have suggested that we might 
instead think of bracketing as inhibiting one's beliefs (knowledge, suppositions, etc.) in order faithfully to quote one's experience. Our aim as phenomenologists is to say how things are according to the experience, and so we must take measures to avoid being influenced by our knowledge (beliefs, etc.) about how things are, period.

At this point, let me dispel a possible misunderstanding. My claim is not that phenomenology has no further aim than to describe our experience. In fact, all phenomenologists have larger, systematic agendas. ${ }^{21}$ Husserl, for example, ultimately wants to inquire into our experiences' conditions of possibility. But whereas the epoché is a necessary precondition for any such transcendental-cum-phenomenological inquiry, the former does not imply the latter. The epoché is not inherently tied to any particular systematic agenda. The epoché enables us to faithfully describe our experiences; but it doesn't tell us what to do with those descriptions.

One notable consequence of this is that we need to distinguish carefully between the epoché and the transcendental reduction. Insofar as the latter is Husserl's method for investigating the conditions for the possibility of world-manifestation (or 'world-constitution'), ${ }^{22}$ it clearly is tied to Husserl's transcendental project. It might also be worth mentioning that the epoché is not inherently bound up with any particular philosophical doctrine either. Thus, even if Husserl (1995, 86) is adamant that 'phenomenology [i.e., his phenomenology] is eo ipso "transcendental idealism"', this is not because of any anti-realistic tendencies built into the epoché. Rather, the 'idealism' in question is supposed to result from 'actual work' (ibid.), that is, systematic phenomenological 'uncovering of the constituting intentionality itself' (ibid.). But the epoché 'does not of itself clarify anything; it is only the gate of entry through which one must pass' (Husserl 1970, 257) in order to be able to start working. And since the epoché can be detached from

\footnotetext{
${ }^{21}$ This takes care of Ayer's objection that 'the mere collecting' of descriptions, 'as a child collects sea-shells, is unlikely to be of philosophical interest' (Ayer 1976, 242).

${ }^{22}$ As argued in Overgaard (2004, chapter 2).
} 
Husserl's transcendental project, it can also be detached from the 'idealism' that results from the carrying out of that project.

As Merleau-Ponty - one of Husserl's best interpreters - pointed out, the phenomenologist's bracketing 'of the world and of the vision of the world which are operative and take form continually within him' initially serves only one purpose: 'to make them speak' (Merleau-Ponty 1964, 4). But one obviously has to record everything one's experiences 'say', including any positions (beliefs) taken towards the experienced object, or towards the world. Inhibiting beliefs is our business qua phenomenologists only, not qua experiencing subjects. We will not understand Husserl's epoché until we have fully appreciated this point. ${ }^{23}$

\section{References}

Alweiss, L. 2013. 'Beyond Existence and Non-Existence'. International Journal of Philosophical Studies 21: 448-469.

Ayer, A. J. 1976. 'Phenomenology and Linguistic Analysis: II'. In H. A. Durfee (ed.), Analytic Philosophy and Phenomenology, pp. 232-242. The Hague: Martinus Nijhoff. Burge, T. 2010. Origins of Objectivity. Oxford: Clarendon Press.

Carman, T. 1999. 'The Body in Husserl and Merleau-Ponty'. Philosophical Topics 27: 205-226.

Carman, T. 2005. 'On the Inescapability of Phenomenology'. In D. W. Smith and A. L. Thomasson (eds.), Phenomenology and Philosophy of Mind, pp. 67-89. Oxford: Clarendon Press. Dennett, D. C. 1991. Consciousness Explained. Boston: Little, Brown and Company.

Fink, E. 2004. 'Operative Concepts in Husserl's Phenomenology'. In D. Moran and L. E. Embree (eds.), Phenomenology: Critical Concepts in Philosophy, Vol. V, pp. 44-58. London: Routledge.

\footnotetext{
${ }^{23}$ I am grateful to audiences at University College Dublin and the University of Hull for comments on some of the material included here. Special thanks to Lilian Alweiss, Joona Taipale, Dan Zahavi, and to two anonymous referees for this journal.
} 
Heath, D. and Heath, C. 2007. Made to Stick. New York: Random House.

Husserl, E. 1969. Formal and Transcendental Logic, trans. D. Cairns. The Hague: Martinus Nijhoff.

Husserl, E. 1970. The Crisis of European Sciences and Transcendental Phenomenology, trans. D.

Carr. Evanston, IL.: Northwestern University Press.

Husserl, E. 1983. Ideas Pertaining to a Pure Phenomenology and to a Phenomenological Philosophy. First Book: General Introduction to a Pure Phenomenology, trans. F. Kersten. The Hague: Martinus Nijhoff.

Husserl, E. 1989. Ideas Pertaining to a Pure Phenomenology and to a Phenomenological Philosophy. Second Book: Studies in the Phenomenology of Constitution. Trans. R. Rojcewicz and A. Schuwer. Dordrecht: Kluwer Academic Publishers.

Husserl, E. 1995. Cartesian Meditations: An Introduction to Phenomenology, trans. D. Cairns. Dordrecht: Kluwer Academic Publishers.

Husserl, E. 1997. Psychological and Transcendental Phenomenology and the Confrontation with Heidegger (1927-1931), Trans. and Ed. T. Sheehan and R. E. Palmer. Dordrecht: Springer.

Husserl, E. 2001. Analyses Concerning Passive and Active Synthesis. Trans. A. J. Steinbock. Dordrecht: Kluwer Academic Publishers.

Kierkegaard, S. 1987. Either/Or, Part I, trans. H. V. Hong and E. H. Hong. Princeton, NJ: Princeton University Press.

Merleau-Ponty, M. 1964. The Visible and the Invisible, trans. A. Lingis. Evanston, IL: Northwestern University Press.

Overgaard, S. (2004). Husserl and Heidegger on Being in the World. Dordrecht: Kluwer. Overgaard, S. 2010. 'Ordinary Experience and the Epoché: Husserl and Heidegger versus Rosen (and Cavell)'. Continental Philosophy Review 43: 307-330. 
Rosen, S. 1999. 'Philosophy and Ordinary Experience'. In Metaphysics in Ordinary Language, pp. 218-239. New Haven: Yale University Press.

Searle, J. 1983. Intentionality: An Essay in the Philosophy of Mind. Cambridge: Cambridge University Press.

Smith, A. D. 2003. Husserl and the Cartesian Meditations. London: Routledge.

Smith, D. W. 2007. Husserl. London: Routledge.

Smith, J. 2005. 'Merleau-Ponty and the Phenomenological Reduction'. Inquiry 48: 553-571.

Sokolowski, R. 1984. 'Quotation'. Review of Metaphysics 37: 699-723.

Sokolowski, R. 2000. Introduction to Phenomenology. Cambridge: Cambridge University Press.

Spiegelberg, H. 1940. 'The “Reality-Phenomenon” and Reality.' In M. Farber (ed.), Philosophical Essays in Memory of Edmund Husserl, pp. 84-105. Cambridge, MA: Harvard University Press.

Steeves, H. P. 2006. The Things Themselves: Phenomenology and the Return to the Everyday. Albany: SUNY Press.

Strawson, P. F. 2011. Philosophical Writings, eds. G. Strawson and M. Montague. Oxford: Oxford University Press.

Wittgenstein, L. 1963. Philosophical Investigations. Trans. G. E. M. Anscombe. Oxford: Blackwell. Zahavi, D. 2003. Husserl's Phenomenology. Stanford, CA: Stanford University Press. 